\title{
From Personal Data to Service Innovation - Guiding the Design of New Service Opportunities
}

\author{
Katharina Blöcher \\ Leipzig University \\ katharina.bloecher@uni- \\ leipzig.de
}

\author{
Fabian Hunke \\ Karlsruhe Institute \\ of Technology \\ fabian.hunke@kit.edu
}

\author{
Rainer Alt \\ Leipzig University \\ rainer.alt@uni-leipzig.de
}

\author{
Gerhard Satzger \\ Karlsruhe Institute \\ of Technology \\ gehard.satzger@kit.edu
}

\begin{abstract}
Stimulated by an ongoing digital transformation, companies obtain a new source for digital service innovation: The use of personal data has the potential to build deeper customer relationships and to develop individualized services. However, methodological support for the systematic application of personal data in innovation processes is still scarce. This paper suggests a comprehensive approach for service design tools that enable collaborative design activities by participants with different data skills to identify new service opportunities. This approach includes the systematic development of customer understanding as well as a process to match customer needs to existing personal data resources. Following a design science research approach, we develop design principles for service design tools and build and evaluate a service opportunity canvas as a first instantiation.
\end{abstract}

\section{Introduction}

In novel data-rich environments [1], a wealth of personal data emerges via smart devices, social media, or various application systems of the enterprise ecosystem [2]. Stimulated by the ongoing digital transformation, personal data become a decisive factor for service innovation and the design of data-driven services. Yet, the general understanding of how services can be designed from data still develops. Although companies are eager to "cash in" on their data [3], they still lack the comprehensive knowledge of how to fully take advantage of data and analytics to expand their portfolio with data-driven service offerings $[4,5]$.

On the way to more human-oriented value co-creation, the emphasis on personal data strengthens customer-centered service innovation processes [6-8]. Organizations can leverage personal data to build deeper customer engagement and to provide customers with contextual, individualized services $[2,9,10]$. However, transforming data into value represents a challenging task: It requires cooperation between cross-disciplinary stakeholders which is often hindered by communication barriers between data spe- cialists and domain experts with different data expertise [11-13]. Including personal data in innovation processes is also complex: Organizations are required to comprehend the variety of customer touchpoints and data sources, where an immense amount of data on customer identities, preferences, and behavior are located $[2,14]$. They must consider privacy regulations and security concerns [15], as well as the active role of the customer to co-create value by sharing valuable information [16, 17]. Therefore, researchers have raised the legitimate question of how personal data can be adequately systematized by design in the conception of new services $[6,9]$. Similar to the concept for privacy by design [18], this signifies the proactive and systematic consideration of personal data already in the design stage of novel services. But while the research interest in data-driven service innovation has been constantly growing $[19,20]$, there is still a lack of academic work focusing particularly on personal data $[6,10,21]$.

Service design takes a human-centered, multidisciplinary perspective and has the potential to foster service innovation processes in organizations [22-23]. The discipline guides the exploration, conceptualization, and evaluation of new service ideas [24, 25] and strengthens collaborative, cross-disciplinary design activities by means of various methods and visual tools. By taking advantage of personal data in innovation processes, valuable customer insights can be derived in the exploration phase and simultaneously converted into information that is useful for the service creation itself $[22,26]$. For this purpose, relevant "data-need fits" must be identified on how personal data can specifically help customers to achieve their personal goals $[10,14]$. We refer to this crucial step of identifying and matching customer needs with data-

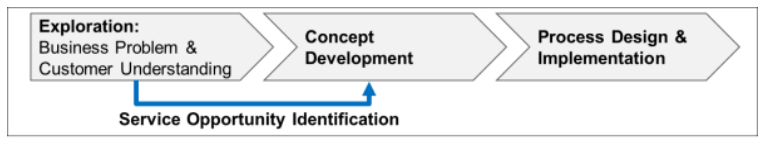

Figure 1. Research focus in the service innovation process, adapted from [24]. 
based value propositions as service opportunity identification, the stepping-stone between the early exploration phase and the conception of new services (cf. Figure 1).

The objective of this work is to develop methodological support through service design tools for the systematic use of personal data during the step of service opportunity identification. Thereby, we understand service design tools as visual inquiry tools including methods, frameworks, or templates that assist in service innovation processes [27]. These tools often serve as boundary objects in collaborative design activities to overcome communication barriers and to encourage cooperation [28]. This paper contributes generic design principles and an instantiation for service design tools in the form of a service opportunity canvas. This initial conceptual knowledge into how service design tools enable the systematic use of personal data provide important implications for 1) researchers, for whom they could serve as guidelines for the design of new tools, and 2) for the tool selection by practitioners. Accordingly, we pursue the following research question to exploit the advantages of personal data for service opportunity identification: RQ: How to develop service design tools supporting the identification of service opportunities by using personal data by design?

Below, we first outline the background and related work of our research in Section 2. We then provide an overview regarding our research design in Section 3. Subsequently, we present the design principles and a possible instantiation of the design knowledge acquired in an actual artifact in Section 4 and 5 . Finally, we describe the artifact's evaluation and discuss its contributions and limitations.

\section{Background and related work}

\subsection{Personal data for value creation}

Personal data denote data that can be linked to a specific person [29] and represent an essential part of the rising big data resources. Personal data include not only demographic or contact information of the individual, but also refer to behavioral data, such as purchase history or device usage data, that can be associated with a person. While this type of data has long been utilized by companies for customer relationship management or data-driven marketing [30, 31], the application of personal data to advance services is still in its infancy [10, 21]. Traditionally, this source of data resulted from transactional processes between organizations and their customers. But the rising number of digital touchpoints and smart devices that people interact with $[2,32]$ has led to an increasing number of digital traces of connected people [10]. Personal data have transformed into a design material itself [33-35] and new types of data-based services emerge, for example for personal assistants, content personalization or self-monitoring services [10, 36, 37]. Yet, the use of personal data is associated with certain requirements: First, deriving comprehensive customer understanding mostly requires data aggregation and integration related to multiple customer interactions $[31,38]$. If organizations strive to build up customer understanding, an integrated view on the customer's individual history is necessary to deduct valuable customer insights [2, 39]. Second, personal data at an aggregate or individual level allow organizations to create personalized service offerings. But the implementation of personalized services involves translating from a customer profile to specific customer segments and applying business rules to provide a variable set of features or service recommendations [40, 41]. Moreover, valuable personal information can also be actively provided by the customer itself [16, 17]. Finally, service providers must ensure privacy regulations as well as data security and need to create trust when working with personal data $[2,15,36]$. Processes for consent management must be defined to ensure compliance with data protection regulations [42]. Consequently, service design tools must not only provide guidance on how to leverage the potential of personal data. They also must consider under which conditions this data can be systematically utilized.

\subsection{Service design tools and personal data}

Service design has evolved into a holistic, multidisciplinary discipline that paves the way for organizations to innovative service solutions [22-23]. The discipline provides a multitude of visual service design tools that often serve as boundary objects for cooperation in innovation processes [28], e.g., service blue printing or customer journey mapping [43-45]. Similarly, the business model canvas represents a prominent example [27, 46]. Nevertheless, most of these tools do not focus on the use of (personal) data, nor do they consider the specific aspects of identifying service opportunities. Research on methodological support that integrates data and analytics more deeply into service design activities is only about to gain momentum [19, 47].

Relevant work occurred in the fields of datadriven service innovation or business modeling: On the one hand, a few tools support in the inspiration phase to understand available data assets as an important resource for new services. This work includes the data canvas [14], the data collection map [48], data service cards [49], the data sphere [50] and customer data mapping [51]. The data collection map and customer data mapping also assist in deriving customer 
knowledge based on (personal) data, but they do not match the resulting customer understanding with the design of value propositions. On the other hand, first service design tools apply a structured process in assessing available data and matching this data to a specific use case or value proposition. The data insight generator [52] and the data value map [53], for example, strive to generate appropriate fits between business value propositions and available data resources. For this purpose, they systematically align this process with necessary data governance aspects and analytical activities. The deduction of customer understanding, or specific customer needs is, however, not the primary focus of these tools. Instead, the data product canvas [47] explicitly incorporates customer needs and challenges as an important prerequisite for working out data products based on analytical methods. Pöppelbuß and Durst [54] develop the smart service canvas as a tool for the design of smart services. They specifically point to the analysis of customers' tasks, context and pains and strive to help companies to analyze their data. By means of the visual structure, the tool aligns customer needs with available data resources to develop data-driven value propositions. But both tools miss the capability to build additional knowledge about the user solely based on the resource of personal data itself. In contrast to these tools, the data innovation board [13] achieves both: the analysis of data resources to deduct customer insights and the matching of data resources with relevant customer needs. Yet, it does not highlight the specific requirements of personal data and ignores, for example, the potential of personalization.

Only a few approaches particularly focus on personal data: Maglio and Lim [6] discuss classifications of data sources and applications as possible starting points for the design of customer-centered services. Kim et al. [21] describe a way using customer behavior data to improve understanding while simultaneously extracting valuable information content for new services. Lim et al. [10] model a process to analyze customer process data and to identify new opportunities for customer value. Other examples are the work of Zheng et al. [55], who focus on user profile, behavior, and feedback data, or Berendes et al. [56] who analyze data-driven customer journeys at the contact points of the customer. But these approaches neither address personalization as an important value driver nor specific requirements of personal data processing. Overall, existing approaches miss out on guiding a systematic identification of service opportunities based on personal data. Consequently, more research is required to derive the expected benefits from personal data for service design endeavors.

\section{Overview of the DSR project}

The objective of this paper is to develop conceptual knowledge for service design tools to provide the basis for a more effective service opportunity identification enabled by personal data. For this purpose, we choose a Design Science Research (DSR) approach as the overarching research paradigm. DSR has proven to be an effective and legitimate paradigm in information systems allowing mediation between practical requirements and theoretical concepts during the research process [57]. Following Hevner [58], a structured approach consisting of three inherent research cycles forms the basis for the research design. A rigor cycle ensures that existing work is integrated into the research project by providing a comprehensive knowledge base. A relevance cycle links the research to the practical context of the application domain, thus eliciting requirements for the research activities from practice. The design cycle takes advantage of the findings of the previous cycles and enforces the design and evaluation of an artifact to solve the addressed research problem.

Following this three-cycle view (cf. Figure 2), we start by building awareness of the underlying practical problem. For this purpose, initial exploratory interviews serve as a starting point and provide first empirical insights. These interviews with IT architects, data strategy consultants, and service operators were conducted within the context of a previous research project [59]. The interviews are used to develop a first understanding of the practitioners' general approach to innovating services based on data and analytics and the problems they encounter. In total, eleven interviews which last 50 minutes on average provide a profound basis to this end [59]. In the second research cycle, we review existing literature on service design, data-/analytics-based services, and business modeling, which we identified as fruitful streams we could consider deducting relevant conceptual knowledge for our research. Based on the insights from both the exploratory interviews and the review, we formulate design

\begin{tabular}{|c|c|c|c|c|}
\hline Environment & Design Science Research & Knowledge Base & (1) Exploratory interviews & Thinking aloud sessions \\
\hline $\begin{array}{l}\text { Application Domain } \\
\text { - People } \\
\text { - Org. Systems } \\
\text { - Techn. Systems } \\
\text { - Problems \& Opportunities }\end{array}$ & \begin{tabular}{|c|c|} 
Build \\
(3) 4 Design Cycle \\
(8) 7 (6) \\
Evaluate \\
\end{tabular} & $\begin{array}{l}\text { Foundations } \\
\text { - Scient. Theories \& } \\
\text { Models } \\
\text { - Experience \& Expertise } \\
\text { - Meta-Artifacts }\end{array}$ & $\begin{array}{l}\text { (2) Problem formulation } \\
\text { (3) Formulating of initial DPs } \\
\text { (4) Service canvas } \\
\text { (5) Ontology development }\end{array}$ & $\begin{array}{l}\text { \& focus group analysis } \\
\text { (7) Expert interviews } \\
\text { (8) User workshop } \\
\text { (9) Design knowledge }\end{array}$ \\
\hline
\end{tabular}

Figure 2. Overview of the DSR approach adopted from [58]. 
principles (DPs) in the design cycle that should be followed when investigating the design of a possible artifact [60]. In this sense, we interpret the respective DPs as a general means to provide guiding knowledge for creating instances of service design tools supporting service opportunity identification infused by personal data [27]. These DPs are subsequently utilized to derive first conceptual components and to prototype a particular instantiation in a canvas-based artifact. As knowledge for designing service design tools to support service innovation activities still develops [22, 61], we choose an iterative three-step evaluation approach and triangulate a mix of different methods to continuously improve our design knowledge and the created artifact via reflection and incremental refinement [60, 62]. First, we conduct thinking aloud interviews [63] combined with a focus group analysis. Second, we interview six domain experts to assess the DPs and conceptual components of the canvas. Based on these learnings, we iteratively adapt the conceptual knowledge and develop an ontology that seeks to visualize the relationships of the concepts in-use [64]. We then improve the design and instantiate a revised canvas that is assessed in a third evaluation episode by means of user workshops.

\section{Conceptualization of design principles}

The design principles (DPs) intend to contribute to the nascent field of personal data usage and represent prescriptive statements for creating instances of service design tools [65]. First empirical insights from the exploratory interviews and theoretical knowledge of the respective academic fields lead to the formulation of first tentative DPs. Following the schema of [66], we define the context and key users for all DPs, i.e., the use of service design tools in collaborative design activities. Key users are participants with different organizational backgrounds and a varying level of data skills. The objective is to identify new service opportunities by systematically using personal data by design. In the following paragraphs, the DPs are formalized and instantiated in a canvas-based artifact.

Related work emphasizes the need to explore, conceptualize and design services from a data-driven perspective $[13,66]$. Service design should embed the language of data [6] and integrate data as the key working principle during the design process. Similarly, the insights from our interviews highlight that data centricity is essential and not yet central enough in the work of service design teams [59]. However, service design represents a human-centered discipline [22] so that tools must integrate both the customer-centric and the data perspective $[6,13]$. Thus, we define the first DP1: Service design tools should combine data- and customer-centric perspectives.

By criticizing traditional means of qualitative research methods, researchers insist that available personal data should be used more intensively to remove 'guess-work' from service design [6, 22]. Service designers aim to understand customers' desires, needs and their individual logic and personal data holds the key to gain valuable insights to improve this understanding. Yet, as the exploratory interviews reveal, extracting this information from personal data is by no means trivial, especially if the data expertise of the team remains limited [59]. To this end, tools should help explore how data can describe the situation of the customer and how this data can be translated into valuable customer insights [21, 23]. Accordingly, we formulate DP2: Service design tools must support on how to use personal data as an additional source of exploration to improve customer understanding.

Companies should establish a process of matching available data resources with user needs [14]. This process can help practitioners reduce the uncertainty perceived by our interviewees about what they should focus on when designing data-driven services [59]. After analyzing and understanding available data sources in detail, organizations must creatively think of new ways data can contribute to pain points and individual objectives of the customer $[13,14]$. Thus, the identification of data-need fits [14] represents a promising approach to incorporate available personal data to create opportunities for new customer-facing value creation. Additionally, service personalization represents an important aspect of the service value chain $[42,67]$ so that a systematic process should incorporate this potential as well. Therefore, tools should fulfil the following DP3: Service design tools should support the matching process between identified customer needs and available personal data to create personalized value to customers.

Visual inquiry tools are nowadays promising means of service design. They have demonstrated their success in collaborative innovation processes by creating a basis for collaboration where team members can use their diverse knowledge and experiences [64]. Tools must provide a shared visualization so that participants can all "refer to the same structure of the problem" [64, p.404]. Similarly, the respondents underline that a shared understanding in collaborative teams is a key to success in designing data-driven services [59]. Moreover, they must enable participants to communicate about data regardless of their level of data literacy $[13,52]$ and must strengthen creativity to think in different directions of data as a design material $[36,50]$. Visual representation provides a way to make 
personal data visible and accessible to enforce creativity for new service concepts [34, 68]. Instead of looking at data records and operational details, service design tools should focus on data use cases [68]. Hence, we specify: DP4: Service design tools should foster creativity for the use of personal data by providing a visual template.

\section{Designing a service opportunity canvas}

To incorporate customer-centric thinking into the new artifact, we start the design process with relevant dimensions of the service concept (DP1). Service concept development is grounded on a strong customer orientation [69]. We are guided by the grounding academic work of Goldstein et al. [70]. Goldstein emphasize the significance of the service concept as a critical step in the service design and development process by representing the mediating element between customer needs and an organization's strategic intent. Following their work, the service concept contains key elements, such as (1) the organization's objectives, (2) the what to deliver (value propositions), (3) the how to deliver, and (4) the identification of customer needs. To manage the "how" of a respective service, the service concept should consider the input resources for the service implementation (e.g., people, technology, data, processes), and the service value outputs including the service encounter at relevant channels. Moreover, to incorporate additional analytical dimensions describing the transformation from data into insights, we take advantage of key dimensions of taxonomies related to analytics-based services or data-driven business models, i.e. (1) analytics, (2) portfolio integration, (3) service user role [71]. In consideration with DP2 and DP3, we add concepts to specifically refine customer understanding when working with the canvas. In line with relevant service literature, we highlight the necessity to comprehend customer processes in detail $[7,10$, $72]$. Moreover, the concept of customer context [8, 73] is integrated to describe the situation of the customer (e.g., family situation, possible preferences) and to collect explorative ideas of how to generate customer insights based on personal data. In correspondence with DP3 we integrate the component of personalization $[40,41]$. These theoretical concepts represent initial conceptual knowledge to work out the design space for service design tools and their components $[27,64]$. To meet the requirements of DP4, we design the artifact as a canvas and arrange the conceptual components in a visual structure.

A preliminary tool has been designed as a first prototype and applied in a first evaluation setting. A second evaluation episode is conducted to concretize the conceptual knowledge for the intended solution

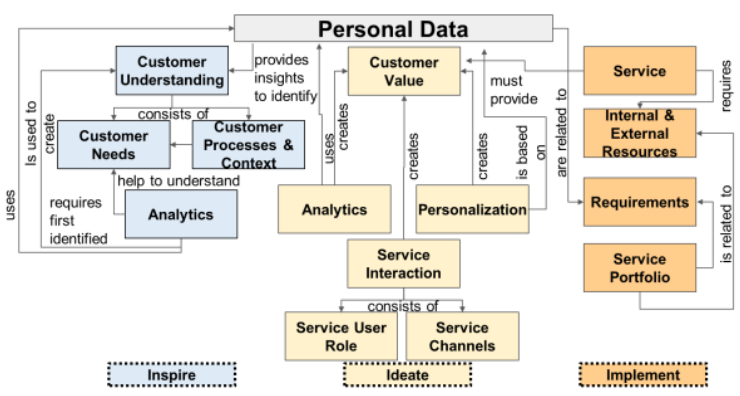

Figure 3. Ontology for service opportunity identification enabled by personal data.

space and to build an ontology following the work of Avdiji et al. [27, 64]. The resulting ontology in Figure 3 describes the main concepts and their relationship to each other. Based on the evaluation results and the ontology, we revise our prototype artifact and adapt its first structure and layout. The revised canvas is presented in Figure 4: As proposed by the interviewed experts, the canvas components are structured along the phases of inspiration, ideation, and implementation of the design thinking process [25]. These phases are established in innovation activities and are considered as suitable to describe the entry points for the systematic application of personal data: The first vertical building block describes the exploration of customer understanding: Inspiration-wise, personal data support the generation of customer understanding by providing insights to understand customer needs, processes, and further knowledge of the customer's situation. Participants should start with already assumed customer needs, e.g., based on surveys, market reports, or personas. Afterwards, participants describe how personal data can be utilized to provide insights regarding customer processes and derive customer context by aggregating existing data, e.g., preferences, practices, or routines as this can additionally help to understand further customer needs. The third component explicitly emphasizes the role of analytics in building customer understanding. Here, participants can gather ideas how analytics can be utilized for generating or validating concrete hypotheses that describe customer

\begin{tabular}{|c|c|}
\hline $\begin{array}{l}\text { Inspire: Customer } \\
\text { Understanding }\end{array}$ & Ideate: Customer Value \\
\hline $\begin{array}{l}\text { Customer Needs } \\
\text { Which hypotheses exist } \\
\text { related to customer needs? } \\
\text { e.g., via surveys, customer } \\
\text { feedback, market reports }\end{array}$ & $\begin{array}{l}\text { Analytics } \\
\text { How can available data and } \\
\text { analytics create new value for } \\
\text { the customer? e.g., via } \\
\text { descriptive, diagnostics, pre- } \\
\text { dictive or prescriptive analytics }\end{array}$ \\
\hline \begin{tabular}{|l|} 
Customer Processes \& \\
Context \\
How can available personal \\
data describe the customer by \\
looking at processes and the \\
context of the customer? \\
\end{tabular} & $\begin{array}{l}\text { Personalization } \\
\text { Can available personal data } \\
\text { be used to personalize the } \\
\text { service? }\end{array}$ \\
\hline \begin{tabular}{|l|} 
Analytics \\
How can analytics support to \\
build up customer \\
understanding, e.g., by \\
generating or validating \\
hypotheses?
\end{tabular} & $\begin{array}{l}\text { Service Interaction } \\
\text { Which are relevant service } \\
\text { channels? Does the customer } \\
\text { consume the service directly } \\
\text { or is a service employee } \\
\text { involved? }\end{array}$ \\
\hline
\end{tabular}

\begin{tabular}{|c|}
\hline Implement: Service \\
\hline $\begin{array}{l}\text { Internal \& External } \\
\text { Resources } \\
\text { Which resources are required } \\
\text { for the service provision? e.g. } \\
\text { data, people, processes, } \\
\text { technology }\end{array}$ \\
\hline $\begin{array}{l}\text { Personal Data } \\
\text { Requirements } \\
\text { What needs to be considered } \\
\text { related to the use of personal } \\
\text { data? e.g., privacy, customer } \\
\text { permission to use data, etc. }\end{array}$ \\
\hline $\begin{array}{l}\text { Portfolio } \\
\text { How can the service be } \\
\text { offered? Single service or a } \\
\text { service wrapped around a } \\
\text { product }\end{array}$ \\
\hline
\end{tabular}

Figure 4. The service opportunity canvas. 
needs for the service design process. In the second ideation block, ideas for value propositions in the form of data-need-fits are collected: The first component invites participants to collect ideas on how data and analytics can create customer value to meet the respective customer needs. Moreover, the component personalization serves for the collection of approaches on how the service can be specifically individualized. Finally, this building block contains the component of service interaction at the service encounter. To reduce complexity, we combine the fields service channels and the service user role into this component whereby the service user role stands for the customer's role in the service provision process, i.e., self-service role vs. interaction with a service employee [71]. In the third building block for service implementation, resources consist of internal or external processes and people, but also other data sources that are not related to the customer. Furthermore, we include the component requirements to address the legal and ethical obligations associated with personal data, e.g., to implement privacy protection measures, data security aspects and consent management [15, 18]. Finally, participants should reflect on how value propositions can be integrated into the existing portfolio and how these decisions affect requirements and resources that are related to the use of personal data.

\section{Evaluation}

\subsection{Evaluation approach}

We design a three-step evaluation approach (cf. Table 2) to gain feedback for the design knowledge and the artifact's contribution in mainly artificial and formative evaluation settings. We choose a criteriabased evaluation approach following DSR and intend to examine 1) the relevance and utility of the artifact, 2 ) its functionality and 3 ) the understandability of the terminology in all evaluation episodes [60, 74, 75]: For the first evaluation episode, we apply the thinking aloud method embedded in a focus group analysis. Originally developed for product-centered usability testing, the thinking aloud method has become a valuable technique in DSR for evaluating users' perception and use of visual inquiry tools [52, 63, 76]. For its application, we invite a multidisciplinary service design team consisting of six participants currently conducting a project on digital service innovation. Following a brief explanation of the procedure, the participants are separately asked to read and talk loudly about their understanding of the artifact's components and share their thoughts on how they would answer each question included in the artifact. We record each interview to generate systematic interview protocols. Next, we set up and moderate a group work followed by a semi- structured focus group interview [77] to get feedback related to our defined criteria. For the second evaluation episode, semi-structured interviews with domain experts at the intersection of service design, CRM, and business innovation are conducted. In a standardized procedure, we asked them to construct the relationship between the components and their logical sequence. With the aid of certain guiding questions, we then discuss the DPs as the conceptual foundation. We integrate the generated knowledge and assess the iteration of the artifact in a third evaluation episode. Here, we organize two separate user workshops and a subsequent semi-structured interview with additional marketing and data experts. Thereby, the evaluation criteria serve as the predetermined guiding question to obtain systematic feedback. The evaluation settings are conducted in different application domains: The first one takes place in an automotive setting. The user workshops focus on a business intelligence service, and specific restaurant services. All evaluation episodes are recorded and transcribed to generate interview protocols for the analysis.

\section{Table 1. Overview of evaluation episodes.}

\begin{tabular}{l|l}
\hline Episode & Participants \\
\hline $\begin{array}{l}\text { 1. Thinking } \\
\text { aloud inter- } \\
\text { views \& focus } \\
\text { group analysis }\end{array}$ & $\begin{array}{l}\text { 6 Participants: Graduates from the } \\
\text { course "Service Design Thinking" with } \\
\text { diverse backgrounds (e.g., engineering, } \\
\text { marketing, service design) }\end{array}$ \\
\hline $\begin{array}{l}\text { 2.Semi- } \\
\text { structured } \\
\text { expert } \\
\text { interviews }\end{array}$ & $\begin{array}{l}\text { 6 Experts: Service design professional, } \\
\text { director co-creation \& innovation, ser- } \\
\text { vice designer for business innovation, } \\
\text { business modeling expert, CRM con- } \\
\text { sultant, CEO customer data platform }\end{array}$ \\
\hline 3. User work- & $\begin{array}{l}\text { 5 Participants: CTO data products, } \\
\text { product owner, UX designer, two data } \\
\text { props }\end{array}$ \\
$\begin{array}{l}\text { 4 Participants: Data scientist \& data } \\
\text { coach, senior user experience re- } \\
\text { searcher, senior marketing expert, CEO } \\
\text { of a start-up for digital services }\end{array}$
\end{tabular}

\subsection{Findings}

Relevance and utility. The evaluation results suggest the utility of the artifact in approaching personal data for service opportunity identification. Interviewed experts underline that the use of data in service design represents an abstract and complex problem. They emphasize the lack of methods and tools in service design - limiting their ability to leverage (personal) data for their activities. The systematic consideration of personal data is described to require a radical rethinking of the discipline but is perceived as a valuable approach as it additionally supports usercentric thinking. Service designers currently start with hypotheses and collect qualitative data, e.g., from lead 
users to evaluate them. The consideration of existing personal data in advance is not embedded in existing processes so that assistance on how to use personal data (DP2/DP3) is perceived as highly valuable. Experts highlight that existing customer relationships should be analyzed to identify new business opportunities and that companies often are not aware of their data treasure. Likewise, the participants of the evaluation episodes underline the need to combine data and user-centric perspectives for data-driven services (DP1). However, they emphasize that it is essential to start with the customers' needs and situation first (DP2/DP3): Customer needs should be known in advance before tapping into the resource of personal data. Even though personal data offer massive opportunities to deduct promising customer insights, service design experts particularly insist that an initial understanding of relevant needs must be in place before analyzing data resources. Furthermore, they add that especially in traditional service-orientated industries, such as the restaurant industry, the combination of both perspectives can lead to a new level of services. The deployment of a visual template in the form of a canvas is appreciated in all evaluation episodes to creatively brainstorm in different directions and to spark collaborative thinking (DP4).

Functionality. All in all, the participants from the focus group analysis and the user workshops are satisfied with their results and the members agree that the artifact helps them identify different service opportunities. During the sessions they develop tangible ideas. In the automotive application setting, the workshop results, for example, in a personalized maintenance service based on driving behavior data, an approach for vehicle diagnostics, or an automatic status report for customers during repair work. Furthermore, the workshop in the restaurant setting leads to an automatic free table alert service, mobility services around the restaurant visit, or individual menus or even long-term diets based on the guest's weight and health condition. This output is valued by the participants as satisfying, and as a sound basis for the development of a more precise design concept. However, the participants from the first focus group analysis point out that specific instructions should support the participants during the development process and that the focus on data-driven services should be clear from the beginning. They suggest that participants should start with a goal before tapping into the world of personal data. After the revision of the canvas, the participants of the final user workshops appreciate the guided process of the iterated canvas to systematically work on service opportunities in a relatively short time and consider that the canvas poses good guiding questions in a structured way. Additionally, they positively report that the canvas supports participants in easily connecting and combining available input to create something new. For further improvements, some participants suggest that a funnel-centric approach is necessary to concretize the brainstormed service opportunities in the second column to further refine those in the last implementation part.

Understandability. Besides the structure, the iteration of the artifact strives to increase the understanding of the canvas. For example, the previous field analytics type including its subcategories was not perceived as intuitive to service designers and required further specification. Similarly, the field service user role was not understood due to unclear terminology. After these amendments, the canvas is assessed as more intuitive, but some participants add that examples are required to explain the partial abstract naming. Moreover, they admit that a moderator is still important to go through the canvas in a group setting as the canvas is (still) not self-descriptive.

\section{Conclusion and future work}

While organizations increasingly possess personal data as a source for meaningful, innovative services, they require assistance in how to tap into this new field. This research relates to academic calls to specifically focus on personal data when designing new services [6, 9] and provides initial design knowledge for visual service design tools in collaborative innovation settings. This work contributes to the body of knowledge on the systematic development of data-driven services using visual collaboration tools [e.g., 13, 52, 54] and complements the perspective on personal data and its peculiarities. By integrating a data-centric perspective deeply into service design activities, this work also provides interdisciplinary knowledge contributions for the service design discipline as requested by $[22,61]$. For this purpose, we introduce initial DPs and an ontology to design individual instances for the respective class of service design tools. The results confirm the initial design knowledge to specifically incorporate the characteristics of personal data into the design process of service opportunities and offer valuable input for future research and the design of visual tools. The conducted research cycles indicate that personal data offer different entry points that need to be aligned by service design tools. Different research directions and organizational roles reflect these perspectives on how to apply personal data. On the one side, personal data are used for exploration purposes to build a deeper understanding of the customer and his needs, e.g., from social media platforms [78]. On the other side, the data is seen as a new 
commodity, which itself is the design material for new value propositions $[4,34]$. Similarly, our research confirms that service designers and experts in data management still operate in separate worlds regarding the use of personal data. However, this paper emphasizes that this "clash of clans" needs to be unraveled by appropriate visual tools. Kurtmollaiev et al. [79] describe the far-reaching effects of service design practices on organizations that can lead to significant changes in mindsets and routines. The use of the intended service design tools has the potential to align different perspectives in organizations by bringing data experts and innovators closer together. Second, we provide a first instantiation for service design tools systematically using personal data by design. The artifact itself can be applied in organizational innovation initiatives. Thereby, the canvas is applicable in the early innovation phase together with other service design tools, e.g., customer journey mapping. Finally, the DPs can offer first assistance for practitioners for the selection of appropriate tools.

Even if the first research cycles generate valuable knowledge for iterative improvements of the artifact and design knowledge, the evaluation provides early empirical results that need more confident and rigorous justification $[64,80]$. First, the artifact requires further assessment: Future research should focus on summative, naturalistic evaluation settings in collaborative groups to gather more data in real-world settings. Subsequent evaluation episodes should take place in different industries to demonstrate the feasibility of the artifact across organizations and should assess the advantages of the artifact compared to other tools. Moreover, the DPs should be further refined and generalized by other researchers to apply the DPs related to different artifacts and to compose design knowledge from multiple perspectives [80]. Further points of consideration for conceptual knowledge are, for example, the categorization of data-driven services [49], or the role and integration of service network partners to exchange valuable data of the customer. Moreover, the aspect of data ownership and privacy by design should be analyzed in more detail. This includes the questions of (1) how deeply a privacy by design approach should be already integrated at the stage of service opportunity identification, and (2) whether organizations should finally own personal data or if the customer holds, manage, and actively share their data for service co-creation $[15,16]$.

\section{References}

[1] Troilo, G., Luca, L.M. de, and Guenzi, P., "Linking DataRich Environments with Service Innovation in Incumbent
Firms: A Conceptual Framework and Research Propositions", Journal of Product Innovation Management 34, 2017 , pp. 617-639.

[2] Kunz, W., Aksoy, L., Bart, Y., Heinonen, K., Kabadayi, S., Ordenes, F.V., Sigala, M., Diaz, D., and Theodoulidis, B., "Customer engagement in a Big Data world", Journal of Services Marketing 31, 2017, pp.161-171.

[3] Wixom, B, "Cashing in on your Data", Research Briefing, 14(8), Center for Information Systems Research, MIT, Cambridge, 2014.

[4] Hunke, F., Seebacher, S., Schüritz, R., and Satzger, G., "Pathways from Data to Value: Identifying Strategic Archetypes of Analytics-Based Services". In Proceedings of the 15th International Conference on Wirtschaftsinformatik. 2020: Potsdam, Germany.

[5] Herterich, M. M., Uebernickel, F., and Brenner, W., "Stepwise Evolution of Capabilities for Harnessing Digital Data Streams in Data-Driven Industrial Services", MIS Quarterly Executive, 15(4), 2016, pp. 299-320.

[6] Maglio, P., Lim, C., "Innovation and Big Data in Smart Service Systems", Journal of Innovation Management 4 (1), 11-21, 2016.

[7] Heinonen, K., and Strandvik, T., "Customer-dominant Service Logic", In the Routledge Handbook of Service Research Insights and Ideas, Routledge, 2020, pp. 69-89.

[8] Alt, R., Ehmke, J.F., Haux, R., Henke, T., Mattfeld, D. C., Oberweis, A., Paech, B., and Winter, A., "Towards customer-induced service orchestration - requirements for the next step of customer orientation", Electron Markets 29(1), 2019, pp. 79-91.

[9] Peters, C., Maglio, P., Badinelli, R., Harmon, R.R., Maull, R., Spohrer, J.C., Tuunanen, T., Vargo, S.L., Welser, J.J., Demirkan, H., et al., "Emerging Digital Frontiers for Service Innovation" Communications of the Association for IS: CAIS 1, 2016, pp. 136-149.

[10] Lim, C., Kim, M.-J., Kim, K.-H., Kim, K.-J., and Maglio, P., "Customer process management" Journal of Service Management 30, 2019, pp. 105-131.

[11] Ermakova, T., Blume, J., Fabian, B., Fomenko, E., Berlin, M., and Hauswirth, M., "Beyond the Hype: Why Do Data-Driven Projects Fail?" In Proceedings of the 54th Hawaii International Conference on System Sciences, 2021, pp. 5081-5090.

[12] Wolff, A., Gooch, D., Montaner, J.J.C., Rashid, U., and Kortuem, G., "Creating an Understanding of Data Literacy for a Data-driven Society", The Journal of Community Informatics, 12(3), 2016, pp. 9-26.

[13] Kronsbein, T. and Mueller, R., "Data Thinking: A Canvas for Data-Driven Ideation Workshops". In Proceedings of the 52nd Hawaii International Conference on System Sciences, 2019, pp. 561-570

[14] Mathis, K., and Köbler, F., "Data-Need Fit: Towards data-driven Business Model Innovation", Service Design Geographies. Proceedings of the ServDes. Conference. No. 125. Linköping University Electronic Press, 2015.

[15] Spiekermann, S., Böhme, R., Acquisti, A., and Hui, K. L., "Personal Data Markets", Electronic Markets, 25(2), 2015, pp. 91-93.

[16] Yi, Y., and Gong, T., "Customer Value Co-creation Behavior: Scale Development and Validation", Journal of Business Research 66, 2013, pp.1279-1284. 
[17] Birch-Jensen, A., Gremyr, I., and Halldórsson, Á., "Digitally connected Services: Improvements through Customer-initiated Feedback", European Management Journal 38, 2020, pp. 814-825.

[18] Cavoukian. A., "Privacy by design: The 7 foundational principles". Information and Privacy Commissioner of Ontario, Canada, 2009.

[19] Engel C., Ebel, P., "Data-driven Service Innovation: A Systematic Literature Review and Development of a Research Agenda". In Proceedings of the 27th European Conference on Information Systems (ECIS), Stockholm, 2019

[20] Demirkan, H., Bess, C., Spohrer, J., Rayes, A., Allen, D., and Moghaddam, Y., "Innovations with Smart Service Systems: Analytics, Big Data, Cognitive Assistance, and the Internet of Everything" CAIS, 2015, pp. 733-752.

[21] Kim, M.-J., Lim, C.-H., Lee, C.-H., Kim, K.-J., Park, Y., and Choi, S., "Approach to Service Design based on Customer Behavior Data: A Case Study on Eco-driving Service Design using Bus Drivers' Behavior Data", Service Business 12 , 2018, pp. 203-227.

[22] Joly, M.P., Teixeira, J.G., Patrício, L., and Sangiorgi, D., "Leveraging Service Design as a Multidisciplinary Approach to Service Innovation", Journal of Service Management, 2019, pp. 681-715.

[23] Ostrom, A.L., Parasuraman, A., Bowen, D.E., Patrício, L., and Voss, C.A., "Service Research Priorities in a Rapidly Changing Context", Journal of Service Research 18, 2015, pp. 127-159.

[24] Kim, K., and Meiren, T., "New Service Development Process", In: Karwowski W., Salvendy G. (eds) Introduction to Service Engineering. Wiley, Hoboken, 2010, pp 253-267. [25] Brown, T., "Design thinking", Harvard Business Review 86(6), 2008, pp. 84-92.

[26] Saarijärvi, H., Grönroos, C., and Kuusela, H., "Reverse Use of Customer Data: Implications for service-based Business Models", Journal of Services Marketing 28, 2014, pp. 529-537.

[27] Avdiji, H., Elikan, D., Missonier, S., and Pigneur, Y., "A Design Theory for Visual Inquiry Tools", Journal of the Assoc. for Information Systems 21, 2020, pp. 1-40

[28] Carlile, P.R, "A Pragmatic View of Knowledge and Boundaries: Boundary Objects in New Product Development", Organization Science 13, 2002, pp. 442-455.

[29] European Commission: The EU Data Protection Reform and Big Data Factsheet, 2016. https://op.europa.eu/en/publication-detail/-/publication/51fc3ba6-e601-

11e7-9749-01aa75ed71a1

[30] Wedel, M., and Kannan, P.K., "Marketing Analytics for Data-Rich Environments", Journal of Marketing 80, 2016, pp. 97-121.

[31] Stone, M., Bond, A., and Foss, B., "Consumer Insight. How to Use Data and Market Research to Get Closer to Your Customer". Kogan Page Publishers, 2004.

[32] Beverungen, D., Müller, O., Matzner, M., Mendling, M., and vom Brocke, J., "Conceptualizing Smart Service Systems", Electronic Markets 29, 2019, pp. 7-18.

[33] Feinberg, M., "A Design Perspective on Data”. In Proceedings of the 2017 CHI Conference on Human Factors in Computing Systems - CHI 17. Denver Colorado, USA: ACM Press, 2017, pp. 2952-63.
[34] Seidelin, C., Dittrich, Y., and Grönvall, E., "Foregrounding Data in Co-design - An Exploration of how Data may Become an Object of Design" International Journal of Human-Computer Studies 143, 102505. 2020.

[35] Seidelin, C., Dittrich, Y., and Grönvall, E., Identification of Data Representation Needs in Service Design. Selected Papers for the IRIS 2017, pp. 16-30.

[36] Huhtala, T., "Using Personal Data to Advance Preventive Healthcare Services". Journal of Service Science Research 10, 2018, pp. 77-115.

[37] Chen, Y., Kreulen, J., Campbell, M., and Abrams, C., "Analytics Ecosystem Transformation: A Force for Business Model Innovation". In: Annual SRII Global Conference, San Jose, California, 2011, pp. 11-20.

[38] Jayachandran, S., Sharma, S., Kaufman, P., and Raman, P., "The Role of Relational Information Processes and Technology Use in Customer Relationship Management", Journal of Marketing 69, 2005, pp. 177-192.

[39] Chan, J.O., "Toward a Unified View of Customer Relationship Management", Journal of American Academy of Business, 2005, pp. 32-38.

[40] Lehrer, C., Wieneke, A., Vom Brocke, J., Jung, R., and Seidel, S., "How Big Data Analytics Enables Service Innovation: Materiality, Affordance, and the Individualization of Service", Journal of Management Information Systems 35, 2018, pp. 424-460.

[41] Fan, H., and Poole, M.S., "What Is Personalization? Perspectives on the Design and Implementation of Personalization in Information Systems", Journal of Organizational Computing and Electr. Commerce 16, 2006, pp. 179-202.

[42] GDPR.EU: GDPR: "Complete guide to GDPR compliance". 2021. https://gdpr.eu/

[43] Shostack, L.G., "How to Design a Service" European Journal of Marketing, 1982, pp. 49-63.

[44] Patrício, L., Gustafsson, A., and Fisk, R., "Upframing Service Design and Innovation for Research Impact", Journal of Service Research 21, 2018, pp. 3-16.

[45] Følstad, A., and Kvale, K., "Customer Journeys: a systematic Literature Review, Journal of Service Theory and Practice, 2018, pp.196-227.

[46] Osterwalder, A., and Pigneur, Y., "Business Model Generation: A Handbook for Visionaries, Game Changers, and Challengers". Wiley, 2010.

[47] Fruhwirth, M., Breitfuss, G., and Pammer-Schindler, V., "The Data Product Canvas: A Visual Collaborative Tool for Designing Data-Driven Business Models", In Proceedings. of the 33rd Bled eConference, 2020, pp. 515-528.

[48] Kayser, L., Mueller, R.M., and Kronsbein, T., "Data Collection Map: A Canvas for Shared Data Awareness in Data-Driven Innovation Projects", Proceedings of the 2019 Pre-ICIS Sigdsa Symposium, 2019.

[49] Breitfuss, G., Fruhwirth, M., Wolf-Brenner, C., Riedl, A., Reuver, M.d., Ginthoer, R., and Pimas, O., "Data Service Cards - A supporting tool for Data-Driven Business" Proceedings of the 33rd Bled eConference, 2020, pp. 600-614. [50] Seidelin, C., Dittrich, Y., and Grönvall, E., "Co-designing Data Experiments: Domain Experts' Exploration and Experimentation with self-selected Data Sources", In Proceedings of the 11th Nordic Conference on Human-Computer Interaction: Shaping Experiences, Shaping Society, 2020, pp. 1-11. 
[51] Blöcher, K., Wittwer, M., and Alt, R., "Customer Data Mapping - A Method for data-driven Service Innovation". In Proceedings of the 15th International Conference on Wirtschaftsinformatik. 2020: Potsdam, Germany.

[52] Kühne, B., Böhmann, T., "Formative Evaluation of Data-Driven Business Models -The Data Insight Generator", In Proceedings of the 53rd Hawaii International Conference on System Sciences, 2020, pp. 427-436.

[53] Sammon, D., and Nagle, T., "The Data Value Map: A Framework for Developing shared Understanding on Data Initiatives", In ECIS: 25th European Conference on Information Systems, 2017, pp.1439-1452.

[54] Pöppelbuß, J., and Durst, C., „Smart Service Canvas Ein Werkzeug zur strukturierten Beschreibung und Entwicklung von Smart-Service-Geschäftsmodellen“, In: Bruhn, M., Hadwich, K. (eds.) Dienstleistungen 4.0. Geschäftsmodelle - Wertschöpfung - Transformation. Band 2. Forum Dienstleistungsmanagement, Springer Gabler, 2017, pp. 91-110.

[55] Zheng, P., Xu, X., and Chen, C.-H., "A data-driven Cyber-physical Approach for Personalized Smart, Connected Product Co-development in a Cloud-based Environment", Journal of Intelligent Manufacturing 24, 2018, pp. 318.

[56] Berendes, C.I., Bartelheimer, C., Betzing, J.H., and Beverungen, D., "Data-driven Customer Journey Mapping in Local High Streets: A Domain-specific Modeling Language", Thirty Ninth International Conference on Information Systems (ICIS), San Francisco, 2018, pp.1-8.

[57] Gregor, S., and Hevner, A., "Positioning and Presenting Design Science Research for Maximum Impact", Management Information Systems Quarterly 37, 2013, pp. 337-355. [58] Hevner, A.: A three Cycle View of Design Science Research. Scandinavian Journal of Information Systems 19 (2), 2007, pp. 87-92.

[59] Hunke, F. and F. Kiefer, "Designing Analytics-Based Services - Exploring Design Requirements for Methodo-

logical Tool Assistance in Service Design Teams", in Proceedings of the 15th International Conference on Wirtschaftsinformatik. 2020: Potsdam, Germany.

[60] Hevner, A.R., March, S.T., Park, J., and Ram, S., "Design Science in Information System Research. MIS Quarterly 28,2004 , pp. 75-105.

[61] Teixeira, J.G., Patrício, L., and Tuunanen, T., "Advancing service design research with design science research". Journal of Service Management, 30(5), 2019, pp. 577-592.

[62] Hussein, A., "The use of Triangulation in Social Sciences Research: Can qualitative and quantitative Methods be Combined. Journal of Comparative Social Work, 1(8), 2009, pp. 1-12.

[63] Ericsson, K. A., and Simon, H. A., "Protocol analysis: Verbal reports as data", MIT Press. (1984)

[64] Avdiji, H., Elikan, D., Missonier, S., and Pigneur, Y.: Designing Tools for Collectively Solving Ill-Structured Problems. In Proceedings of the 51st Hawaii International Conference on System Sciences. 2018, 400-409.

[65] Gregor, S., Kruse, L.C., and Seidel, S.," The Anatomy of a Design Principle", Journal of the Association for Information Systems 21(6), 2020, pp. 1622-1652.

[66] Kühne, B., Böhmann, T., "Requirements for Representing Data-Driven Business Models - Towards Extending the Business Model Canvas”, AMCIS Proc., 2018, pp.1-10.
[67] Rust, R.T., and Huang, M.-h., "The Service Revolution and the Transformation of Marketing Science". The Marketing Journal of the Institute for Operations Research and the Management Sciences 33, 2014, pp. 206-221.

[68] Winter, R., "Blackboxing Data: Conceptualizing DataDriven Exploration from a Business Perspective". In: Bergener, K., Räckers, M., Stein, A. (eds.) The Art of Structuring. Bridging the Gap between Information Systems Research and Practice, Springer, Cham, Switzerland, 2019, pp. 153-163.

[69] Edvardsson, B., and Olsson, J., "Key Concepts for New Service Development", The Service Industries Journal 16, 1996, pp.140-164.

[70] Goldstein, S.M., Johnston, R., Duffy, J., and Rao, J., The service concept: the missing link in service design research?" Journal of Operations Management 20, 2002, pp. 121-134.

[71] Hunke, F., Engel, C., Schüritz, R., and Ebel, P., "Understanding the Anatomy of Analytics-based Services - A Taxonomy to Conceptualize the Use of Data and Analytics in Services", In Proceedings of the 27th European Conference on Information Systems, 2019, pp. 8-14.

[72] Bettencourt, L.A., "Service Innovation: How to Go from Customer Needs to Breakthrough Services" McGrawHill Professional, 2010.

[73] Bazire, M., and Brézillon, P., "Understanding Context Before Using It" In: Dey, A., Kokinov, B., Leake, D., Turner, R. (eds.) Modeling and using context. Springer, Berlin, Heidelberg, 2005, pp. 29-40.

[74] March, S.T., and Smith, G., F., "Design and Natural Science Research on Information Technology", Decision Support Systems, 1995, pp. 251-266.

[75] Venable, J., Pries-Heje, J., and Baskerville, R., "A Comprehensive Framework for Evaluation in Design Science Research". In: Peffers, K. (ed.) Design Science research in Information Systems. Advances in Theory and Practice: 7th international Conference: Proceedings, Springer, Heidelberg, 2012, pp. 423-438.

[76] Boren, T., Ramey, J., "Thinking aloud: Reconciling Theory and Practice”, IEEE Trans. Profess. Commun. 43, 2000, pp. 261-278.

[77] Tremblay, M.C., Hevner, A.R., and Berndt, D.J.: The Use of Focus Groups in Design Science Research. In: Hevner, A.R., Chatterjee, S., Gray, P., Baldwin, C.Y. (eds.)

Design Research in Information Systems. Theory and Practice, Springer, New York, 2010, pp. 121-143.

[78] Kühl, N., Scheurenbrand, J., and Satzger, G., "Needmining: Identifying Micro Blog Data Containing Customer Needs", In Proceedings of the 24th European Conference of Information Systems, 2016, pp. 1-16.

[79] Kurtmollaiev, S., Fjuk, A., Pedersen, P.E., Clatworthy, S., and Kvale, K., "Organizational Transformation Through Service Design”. Journal of Service Research 21, 2018, pp. 59-74.

[80] Vom Brocke, J., Winter, R., Hevner, A., and Maedche, A., "Accumulation and Evolution of Design Knowledge in Design Science Research: A Journey Through Time and Space", Journal of the Association for Information Systems 21, 2020. 